\title{
Experiencing Market Dynamics with TraderEx: A Trading Decision- Making Simulation
}

We have presented the case in this book that trading education is important for success in the securities and investments industry. Are apprenticeships and time on an institutional trading desk the only way to learn how to trade? Do you need to work with real orders and have real money at risk to gain experience interacting with the dynamic process of price formation? The answers are no and no. Trading simulations that are well-designed can create experiences with price discovery and impose the challenges of illiquidity in ways that replicate the learning accomplished (and pressures felt) on a real trading desk. With TraderEx, you will appreciate the complexity of trading and understand it as a distinct profession within the financial industry, even if it is not always thought of as such in business school curriculum. ${ }^{1}$

Our years of experience teaching with the TraderEx trading simulation system have shown that it is an excellent way to "bring to life" many of the concepts presented in this book. TraderEx creates a market order flow and a realistic environment in which you can experience how price discovery takes place and liquidity fluctuates. You will observe and understand that you should trade differently under different market structures. TraderEx can be played solo in a solitaire session or in the advanced version, trading can occur among multiple players in a networked session. It accommodates the three main types of market structures that we have discussed in the previous chapters: order-driven, quote-driven, and call auction.

In this section, we focus on four critical realities that can be brought to life via TraderEx. The TraderEx simulation is intended to enable you to:

- Understand that market prices commonly do not equal equilibrium values.

- Find out how your own trading decisions can impact market prices.

\footnotetext{
${ }^{1}$ The software for TraderEx current version was developed by Andrew Novocin, Ph.D., in JavaScript and Firebase, a cloud-hosted database. The statistical model used in TraderEx was developed by Schwartz and Weber and first implemented in SimScript II.5 in 1991.
} 
- Experience the varied environments of different market structures (i.e., market structure matters).

- Assess the costs of illiquidity - In a highly liquid market, trading is cheap and easy, but markets are commonly less than perfectly liquid.

Our focus in this chapter will be the order-driven market structure. In this structure, the orders of some participants establish the prices at which other participants can trade. Any participant can "supply" liquidity by entering limit orders or can "consume" liquidity with market orders. This differs from a "quote driven" market where dealer quotes establish the prices at which other participants can trade. In a pure dealer market, the dealers are the only source of liquidity, and other participants trade at the dealer quotes (by placing market orders) only.

Order-driven markets have two forms: "continuous" and "periodic." Continuous means that a trade can be made at any point in continuous time when a buy order matches or crosses a sell order in price. For example, if you are willing to buy 100 shares at a \$20 limit price while I am willing to sell 100 shares now at \$20 and our orders meet when the market is open, a trade will occur.

Periodic trading is referred to as "call auction trading." In the call auction environment, orders are not executed even if they meet or cross in price until the market is "called." The call and continuous market structures offer different advantages, and in today's electronic exchanges, they are generally combined in a hybrid market environment. To keep things simple, we will focus on continuous market trading only in this chapter.

\subsection{Conceptual Features of the TraderEx Trading Simulation}

Trading simulations enable you to gain experience making trading decisions without risking actual money. TraderEx provides a market structure, which is the set of rules for matching buy and sell orders to create trades, and the software generates a stream of orders. To be realistic and engaging, a trading simulation must have four properties:

1. The computer-generated order flow must capture the pricing dynamics of a realworld marketplace.

2. The simulated market must give you some basis for anticipating future price movements.

3. The software must enable you to replay a simulation run so that you can see the effect of a change of your strategy, or of the market structure, or of the parameter settings (e.g., volatility, order arrival rate, etc.)

4. The simulation must provide you with meaningful performance benchmarks to compare with others and to get feedback on how you are improving with experience. 
TraderEx's computer-generated order flow is based on draws from various statistical distributions. The most important determinant of the market's dynamics is the equilibrium price, which we call $\mathrm{P}^{*}$ (" $\mathrm{P}$-star"). $\mathrm{P}_{\mathrm{t}}^{*}$ is the valuation at time $\mathrm{t}$ of the stock based on full information and no economic frictions. Of course, new information arrives over time that affects the $\mathrm{P}^{*}$ value, but these shocks are unpredictable and the changes that raise and lower the equilibrium value are balanced, making the evolution of $\mathrm{P}^{*}$ a driftless random walk process. In a hypothetical world with costless trading and complete, instantaneous information dissemination, price adjustments are instantaneous, one-shot events. The market price would always be $\mathrm{P}^{*}$. In real-world markets, informationally motivated orders arrive at the market sequentially, and price adjustments are noisy and non-instantaneous.

Along with the simulation's random information events and their changes in the stock's underlying value $\left(\mathrm{P}^{*}\right)$, there are economic forces driving the three classes of traders in the simulation:

Informed traders: they are motivated to trade by the arrival of news that causes $\mathrm{P}^{*}$ to be greater than market prices (informed buying) or to be less than market prices (informed selling).

Liquidity traders: they are motivated by their own cash flow needs and individual, uninformed reassessments of share value.

Technical traders: they are motivated by their beliefs that they have observed exploitable patterns in the stock's price movements.

The arrival rates for orders and events can be modeled as statistical processes. The arrivals of information-driven and liquidity-driven orders are modeled with the use of a stochastic process known as the Poisson arrival process. What moves the market into alignment with $\mathrm{P}^{*}$ is the one-sided trading of informed participants. When the $\mathrm{P}^{*}$ valuation is greater (or less) than the stock's market price, informed orders are motivated to buy (sell) and will continue to trade in a single direction until market quotes straddle $\mathrm{P}^{*}$. For example, if $\mathrm{P}^{*}$ is $\$ 22.50$ and the market bid-ask is $\$ 22.40-\$ 22.60$, there is no informed trading opportunity, but if $\mathrm{P}^{*}$ jumps above the $\$ 22.60$ ask, informed buy orders will kick in until the market price rises to the level of $\mathrm{P}^{*}$. If $\mathrm{P}^{*}$ drops below the $\$ 22.40$ bid, informed sell orders will kick in. In TraderEx, price changes reflecting new information take place sequentially, and consequently, with liquidity and technical traders also on the scene, realized transaction prices are blurred and noisy signals of $\mathrm{P}^{*}$.

The magnitude of information change, when it occurs, is reflected in the size of the jump in the fundamental value, $\mathrm{P}^{*}$. Each change in $\mathrm{P}^{*}$ is an investment return to holders of the stock. $\mathrm{P}^{*}$ jumping up (a positive return) is good news that means that the stock has a greater value, while $\mathrm{P}^{*}$ dropping down (a negative return) is bad news for holders of the stock. In our TraderEx simulation, the $\mathrm{P}^{*}$ returns are lognormally distributed with a mean of zero as the default setting.

Over any simulation run, $\mathrm{P}^{*}$ may drift up or it may drift down, but with a mean return of zero, there is no systematic tendency for it to move in one direction or the 
other over any simulation run. We can change the impact of the information events, and thus the underlying level of market volatility, by changing the variance parameter of the lognormal return distribution. Because the $\mathrm{P}^{*}$ returns are obtained by random draw, successive changes in $\mathrm{P}^{*}$ are not serially correlated. That is, $\mathrm{P}^{*}$ moves randomly through time, and thus, our equilibrium price follows a random walk.

When $\mathrm{P}^{*}$ is above the offer (or below the bid), the arrival rate of market orders to buy (or to sell) is increased from $50 \%$ to $67 \%$ of the total order flow. When $\mathrm{P}^{*}$ is below the bid, there will be, on average, twice as many sell orders as buy orders, and when $\mathrm{P} *$ is above the offer, there will be, on average, twice the number of buy orders as sell orders. When $\mathrm{P}^{*}$ is between the bid and the offer, no informed orders are generated, and market orders to buy and to sell are entered by liquidity traders with equal probability.

The liquidity orders in TraderEx are equally likely to be buy orders or sell orders, and the assignment for each newly generated liquidity order is done randomly and independently. Whatever motivates them, the important thing for us is that these orders are uncorrelated with each other and with the information orders. Recognizing this, the "liquidity motive" includes all reasons that are unique to an individual and represent each trader's own, individual reassessment of share value.

TraderEx incorporates a type of technical trader, a momentum player. Momentum trading is an essential component of TraderEx. Without some noise from uninformed traders, it would be too easy for you to detect $\mathrm{P}^{*}$ shifts from the evolution of trade prices. This is because any jump in $\mathrm{P}^{*}$ that puts it above the offer (or below the bid) triggers a preponderance of machine-generated market orders to buy (or market orders to sell), and these market orders cause prices to run up (or to run down) toward the new value of $\mathrm{P}^{*}$, but then stop once prices are again in equilibrium. This pattern must be obscured in some way, or you could profit too easily by buying or selling whenever price appears to be trending up or down. We do not want you to be a monopolist with respect to this strategy, and momentum trading is the answer because it will compete with you if you try to jump on a trend by buying when the quotes rise or by selling when they fall.

Further, with momentum traders on board, trends can be misleading. The momentum-driven orders raise uncertainty for you by reinforcing false, unsustainable price moves that are not driven by $\mathrm{P}^{*}$. Prices in TraderEx can trend up due to several liquidity-motivated buy orders arriving by chance. And the overshooting relative to $\mathrm{P}^{*}$ caused by momentum orders is necessary for limit orders to be submitted. This is because overshooting enables a larger set of limit orders to execute, not just those at the best bid and offer, and for the limit order placer to profit from price then reverting back toward its previous level. A relatively wide bid-ask spread also provides this kind of compensation. In other words, the TraderEx simulation mimics the ecology of a real-world stock market where different traders trade based on their varied motives and expectations. 


\subsection{Using the TraderEx Trading Simulation}

The most straightforward way to use the TraderEx system if you are on your own is to use the "Order Book" version and by clicking the "Solitaire Session" option. This limited functionality version is available at https://demo.etraderex.com/ (Exhibit 5.1a).

When you click the start arrow " $\rightarrow$ ]" displayed in Exhibit 5.1b, the system will initiate the simulation and automatically populate the order book with limit orders like the one described in detail in the Finance chapter. Once you press the red "Start" button, the system clock will start, and you will see dynamic updates to the order book as orders from the computer program (and in the networked version when live participants) arrive. An image of this limit order book is presented in Exhibit 5.2.
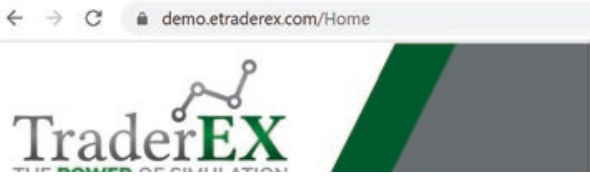

demo.etraderex.com says

Set Your New Name:

BRUCE|

Exhibit 5.1a TraderEx landing page after selecting "Sign In Anonymously"

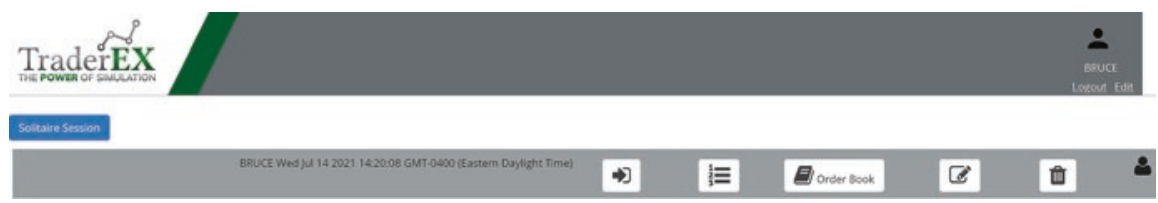

Exhibit 5.1b After using "Edit" to enter your name, click on "Solitaire Session" to create a single-use order book simulation

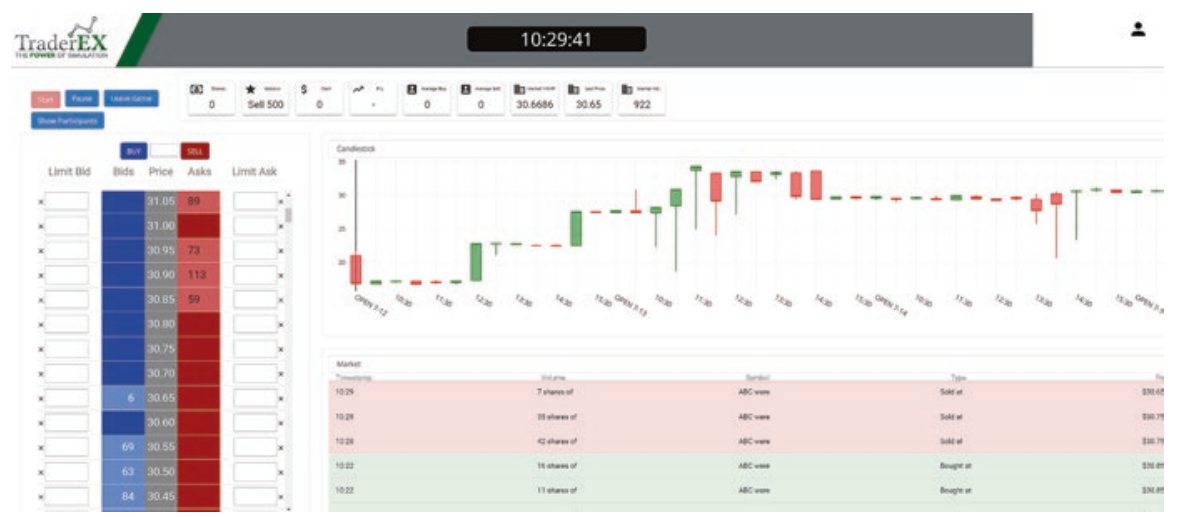

Exhibit 5.2 Limit order book from TraderEx simulation 
Exhibit 5.2 displays a set of orders that drive a continuous, order-driven market. The left-hand side shows orders that have been posted on "the book." The book is the market. It has three columns: the middle column displays a price ladder (from the highest down to the lowest); the column to the left shows, at each price, the number of shares sought for purchase (a share in TraderEx is a "round lot" that corresponds to 100 shares in an actual stock market); and the column to the right of the price ladder shows, at each price, the number of shares offered for sale. The chart shows three prior days of simulated price action with a Candlestick display that shows green or red every 30 min depending on whether the price rose or fell in that time window.

Look at the blue, gray, and red columns on the left of Exhibit 5.2. What strikes you? Notice that the selling prices are all higher than the buying prices. Why, you might ask, has no seller stated a willingness to offer shares at a price lower than the most aggressive buyer is willing to pay, or that no buyer is willing to purchase shares at a price higher than the most aggressive seller has offered to part with shares at? What accounts for this? The answer is simple. In the continuous market, a trade occurs if the prices stated on a buy order and on a sell order meet or cross. As the trade is being made, these orders are "executed," and executed orders no longer appear on the book. The book, therefore, contains only sell limit orders that are posted above the limit buys and buy limit orders that are posted below the limit sells. In TraderEx, when there are multiple limit orders making up the displayed quantity at a price, the priority rules for which orders trade kick in. The first priority rule is price priority: the most aggressively priced orders (the highest priced buys and the lowest priced sells) execute first. The second priority rule is time priority: when multiple orders are at the same most aggressive price, the earliest arriving orders have priority over the later arriving orders.

Below the price chart in Exhibit 5.2, TraderEx provides a scrolling blotter of all trading in the market. Trades are reported live, and then they scroll down as new trades occur. The blotter entries are either green or red, with green indicating trades that were triggered by arriving buy orders that executed against limit orders to sell that were resting in the book. Red rows show trades that were triggered by sell orders arriving and executing against buy orders that were resting on the book. By clicking on the rectangle above the blotter, you can toggle between Market and User, which will filter the blotter to show only the user's trades. Above the blotter is a price chart with 3 days of price information. The chart allows the user to toggle between a Candlestick display and a Line display.

Once you comfortably understand how the book displays the posted buy and sell orders, let us enter this market and trade. But first, doing so requires knowing the order types available to you and how to submit them.

\subsection{Orders Types}

As Chap. 2 explains, the two most important order types are market orders and limit orders. We can think of limit orders as "price contingent orders." They trade (or not) contingent on the market price reaching the limit price and a counterparty order 
arriving. A multiplicity of other order types exists - stop orders, market-on-close orders, hidden orders, etc. - but they are not essential to the operations of an orderdriven market. Market and limit orders are essential. Let us focus on them.

We have discussed Exhibit 5.2 and how buy and sell orders are posted on either side of the price ladder. Are these limit orders or market orders? Consider the buy orders at 30.65 and 30.55, which summed together are for 75 TraderEx shares. What kind of orders are these? Answer: limit orders. Why are they called "limit orders"? First, these are priced orders - the prices being $\$ 30.65$ and $\$ 30.55$. What is each price saying? According to the first trader's instruction, those 6 shares should be bought at any price of $\$ 30.65$ or lower. In other words, $\$ 30.65$ is the maximum the buyer is willing to pay. As a maximum, it is setting a limit: "I am willing to pay up to $\$ 30.65$ but not a nickel more."

What about on the sell side? The interpretation of a posted sell order is the same as that of a posted buy order, but with one exception: the price limit on a sell order is a minimum, not a maximum. For instance, the sell orders placed at a price of $\$ 30.85$ account for a total of 59 shares that are for sale only if they can be sold at a price of $\$ 30.85$ or higher (but not for one nickel less!).

Conclusion: limit orders are called because they are priced, and the prices are limits: a maximum limit for buy orders and a minimum limit for sell orders. To solidify your grasp of these maximum and minimum limits, refer back to Exhibit 5.2 and calculate the total number of shares that, given the book, can be bought up to a price of $\$ 30.90$ or sold down to a price of $\$ 30.50$ (A: 172 and 138).

Let us introduce some additional terminologies.

- Limit order book: We have been referring to the columns on the left-hand side of Exhibit 5.2 as the "book." Because the book contains limit orders, it is commonly referred to as the "limit order book."

- Quotes: The prices of the most aggressively priced orders (highest priced buy order and lowest priced sell order) on the book are commonly referred to as "quotes."

- Offer price: This term is sometimes used instead of "ask" price.

- Best bid and offer: This is sometimes referred to as the BBO or the "inside market," or as the "inside quotes."

- Bid-ask spread: The lowest ask quote minus the highest bid quote is the spread.

On to market orders. You have an alternative to entering limit orders in the TraderEx marketplace. You can also submit market orders. This is an unpriced order that reflects a simple statement: "I want to buy or to sell X number of shares at the market price." When submitting a market order, you would certainly want to know what the best prices on the book are, for these prices define "the market."

So look again at Exhibit 5.2 and identify the best price that a market order to buy or to sell would transact at. Answer: the lowest ask price (for a buy order) and the highest bid price (for a sell order). However, we point out two provisos. First, if you enter a market order for a larger number of shares than the number posted at the best bid or ask, it will execute only partially at this best price, and the remainder will 
"walk the book" to less aggressive prices (up the book for a larger buy order and down the book for a larger sell order). The second proviso is that while you are in the process of submitting your order, some other orders may shoot in ahead of you, transact against the book, and result in your order executing at a price inferior to what you had expected. If that happens to you while playing TraderEx, you will better understand why equity market traders put great value on the speed with which they can get information and act on it.

\subsection{Running a TraderEx Simulation}

Let us go ahead and complete an instruction: buy 500 shares over the course of one trading day (9:30-16:00). Looking at Exhibit 5.3, we see that buying the full order immediately by market order would "crash through" the 20.90 and 20.95 bids and drive the price up down to $\$ 21.00$. To avoid that costly market impact, we enter a market order to buy 12 from the limit orders to sell and place a limit order to buy at $\$ 20.85$.

In TraderEx, you begin the day with a zero share position and zero cash, and no commissions are charged. This keeps the focus on your trading and the prices you realize. Our market order to buy 12 shares executed at $\$ 20.95$ at 9:39. We have an obligation to pay and therefore have a cash position of $-\$ 251.40$. Notice that TraderEx computes a P/L (profit and loss) using a "mark-to-market" formula. Mark-to-market of a short position is done by multiplying the share position by the current best ask and subtracting that from what was generated when we sold the shares. We, however, are long 12 shares and will mark to market at the highest bid to calculate the revenue from selling the 12 shares. That is $12 \times 20.85=\$ 250.2$ and therefore, our $\mathrm{P} / \mathrm{L}$ is $-\$ 0.60 \$ 60.00$ if we factor in that these are round lots of 100 .

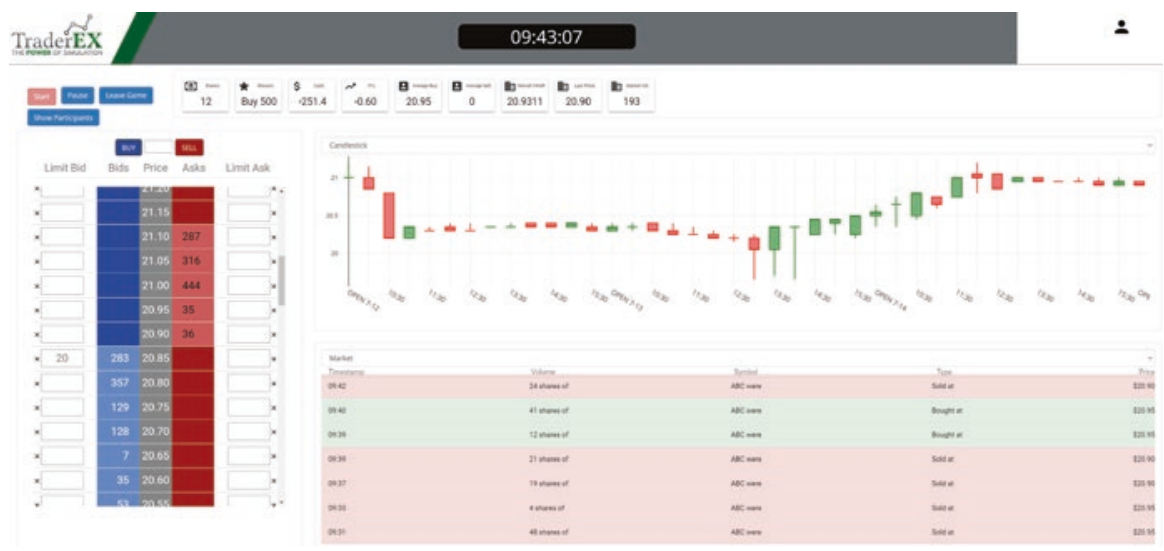

Exhibit 5.3 Limit order book from TraderEx simulation - The user's instruction is to Buy 500 by the end of the trading day 
Over the rest of the trading day, how do we know how we are doing as we execute our sell orders? A number of transaction cost analysis methods exist, but we will focus on one - VWAP benchmarking. VWAP stands for volume weighted average price and is calculated by dividing the total value of trades during the day by the number of shares traded. For example, if 100 shares trade at $\$ 20.00$ and 300 shares trade at $\$ 19.80$, the VWAP is $\$ 19.85 .^{2}$ To complete an instruction to buy a large quantity over the course of a day and pay an average price per share that is less than VWAP is an accomplishment. Similarly completing a large number of sell orders and finishing with an average price per share sold above the VWAP is a success.

Exhibit 5.4 shows the situation at 1:58 pm. We have bought 380 shares and have resting limit orders for 45 of the remaining 120. The average buying price we have paid so far is \$21.4293, and the VWAP is \$21.2676. In what has been a rising market, we have paid about 16 cents more than VWAP. So far, not so good, but two more hours of trading remains.

The end-of-day display in Exhibit 5.5 shows that 6,093 shares traded, and the last trade was at $\$ 21.20$. Our trading (500) made up about $8 \%$ of the day's volume. Our buying prices averaged $\$ 21.4078$ per share compared to the market VWAP of $\$ 21.3077$. We finished our instruction to buy 500 and were not able to improve on the VWAP price. In a difficult, rising market, we bought for 10 cent more than VWAP. We'll do better next time. Those 10 cents will reduce whatever returns result from holding these 500 shares. If we had been able to buy 10 cents below VWAP, we would add $\$ 0.10 \div \$ 21.3077=+0.47 \%$ to the performance of the investor from this stock holding.

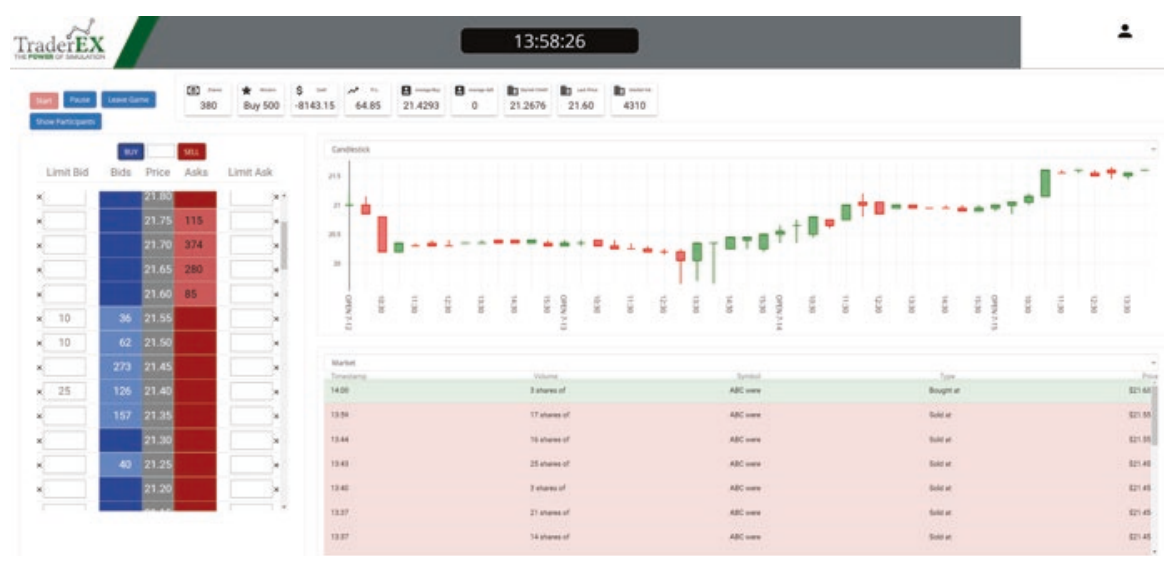

Exhibit 5.4 About two hours remain in the TraderEx simulation

\footnotetext{
${ }^{2}$ The VWAP calculation is Value Traded $(\$) \div$ Volume Traded (shares) $=(100 \times \$ 20.00+$ $300 \times \$ 19.80) \div(100+300)=\$ 19.85$.
} 


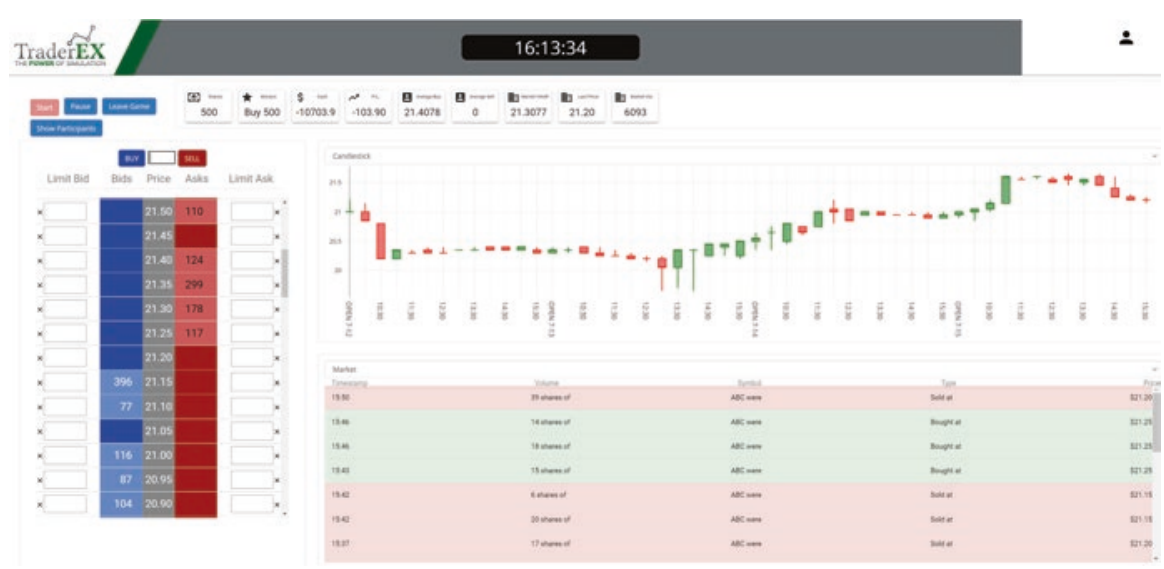

Exhibit 5.5 End of the simulated day of trading

Notice also that the $\mathrm{P} / \mathrm{L}$ is negative. To see why this is, consider that our buying 500 at an average price of $\$ 20.4078$ cost us $\$ 10,703.90$. The last price in the market was 21.20 , so selling 500 at that price would generate 10,600 , and therefore, we have a $\mathrm{P} / \mathrm{L}$ of $10,703.90-10,600=-\$ 103.90$

To recap, we played the TraderEx simulation as a buy-side trader with a mandate to buy or to sell a certain number of shares during the trading day. ${ }^{3}$ Typically, traders who work for an investment management firm would have an instruction or ("mission") to buy or to sell a specific number of shares to help the fund under their management accumulate or reduce a position for their investors. These participants are the "buy-side" traders. In this case, as shown in Exhibit 5.5, the player used the number in the "Mission" display box as their goal for the trading day. For this example, the Mission box indicated "Buy 500," and the trader bought 500 shares of the security before the end of the trading day and, unfortunately paid a higher price than VWAP.

Exercise 1 Go to the website (https://demo.etraderex.com/) and create a TraderEx Solitaire Session. Then launch the simulation with the right arrow icon. There will be a slight delay initializing the simulated market before the Start button is active. You will be given a mission to buy or to sell a certain quantity shown under "Mission." You will have the 9:30-16:00 (4 pm) trading day, which will be simulated in about 10 minutes, to complete it. To begin completing your instruction after the market starts, enter a market order two times larger than the number of shares offered at the best market quotes (if the inside quote is for 90, enter a market order for 180) and determine the prices at which it executes. This will probably not be a good trade for you because of market impact, which has been referred to as the "price concession an investor may be forced to make for trading in quantities greater than those associated with the posted bid or ask price." In the TraderEx marketplace,

${ }^{3}$ More detailed definitions of the buy- and sell-side participants can be found in Chap. 2 . 
you will have market impact if you bang into the book with sufficiently large market orders. The orders that you executed are displayed by clicking on "User" at the bottom of the price chart on the screen. Continue trading to reach your target position. The market will close at $4 \mathrm{pm}$. How did you do? Did you acquire the target position? How does your average price for selling or buying compare to VWAP?

Exercise 2 Repeat Exercise 1 but without placing the large initial market order. Did you improve your outcome when you did not start the day with a large market order?

Exercise 3 A player can also participate in the game by placing limit buy (or "bid") orders on the left-side column and limit sell (or "ask") orders in the right-side column. In Exhibit 5.6, you have placed 80 shares to buy at a limit price of $\$ 21.45$ and 90 shares to sell at $\$ 20.60$. This type of order placement strategy could be effective for those playing the game as a proprietary trader or "market maker" whose goal is to capture the $\$ 0.15$ spread between their bid and ask while not letting their positions get too large and risky. Most "prop traders" want to finish the day with a "flat book" or zero position in the stock to avoid overnight risk. If successful, you might be able to make round-trip profits of $\$ 0.15$ per share. What could go wrong? To find out, start a new TraderEx session and run it. Ignore the "Mission" that is provided and seek to earn trading profits by two-sided trading to capture the spread. Bring your position back to zero by the market close at 16:00. How did you do in terms of P\&L and the number of shares that you traded? What else may have affected your trading? The size of the spread, risk/position size, time remaining in the trading day? Anything else?

Exhibit 5.6 A market making strategy to earn trading profit from posting two-way limit orders to both buy and sell

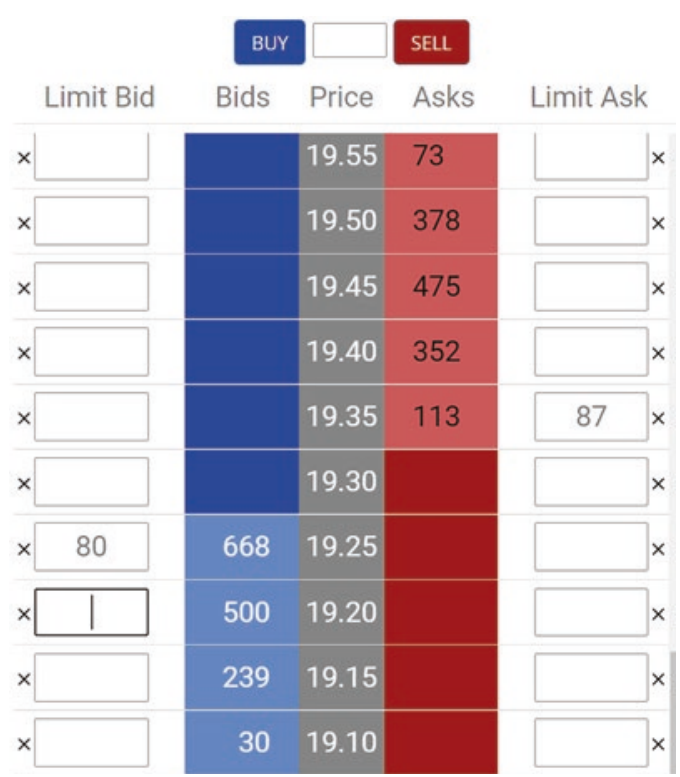


Exercise 4 An alternative strategy is to study short-term market momentum and use the "Buy" and "Sell" buttons at the top of Exhibit 5.6 to place market orders when you see the market trending up or down. For instance, if the bid rises to a new, higher level that suggests buying pressure is building, then enter a market order to buy. Later you hope to sell your newly bought shares at a higher price. Although market orders execute swiftly, the downside is that you pay the bid-ask spread on any round-trip trade (i.e., you buy at the higher ask price and then sell at the lower bid price). Market orders are best used by players who need to act quickly on new information, or who are looking to close out their positions so that, at the end of the day, they are neither long nor short the security. If you are playing the game as a trend follower or speculator, then it might be worth paying the bid-ask spread by placing a market order if it helps you catch a short-term trend in the market. Create a new TraderEx session and run it. Ignore the "Mission" that is provided and seek out trading profits by trading with market orders when an uptrend or downtrend emerges. Bring your position back to zero by the market's 16:00 close.

\subsection{Diving Deeper}

After the TraderEx simulation is completed for the trading day, you can click the results icon ("1., 2., 3.") to your goals. For example, a buy-side trader's shares should reflect their mission, and ideally, the average price will be close to or better than the market VWAP (Exhibit 5.7).

At the end of a trading session, a buy-side trader should have a position equal to the number of shares displayed in the Mission box (and, of course, with the correct sign). That is, the buy-side trader should finish with +500 shares if the Mission box indicates "Buy 500" and, conversely, with -500 shares if the Mission box displays "Sell 500." These buy-side traders can then be evaluated according to their Buy VWAP (average buy price) vis-à-vis the market's overall average price (Market VWAP). When their mission is to "buy," it is a good result when their "average buy" price is lower than the market's VWAP. In contrast, if their mission is to "sell," then their "average sell" price should be higher than the Market VWAP. In contrast, a market maker's net position should be zero at the end of the day while ideally earning a positive profit (as shown by the "Shares" and "P/L" columns). A trend-following proprietary trader might also finish with a zero position, and show a positive P/L (profit/loss) if they made

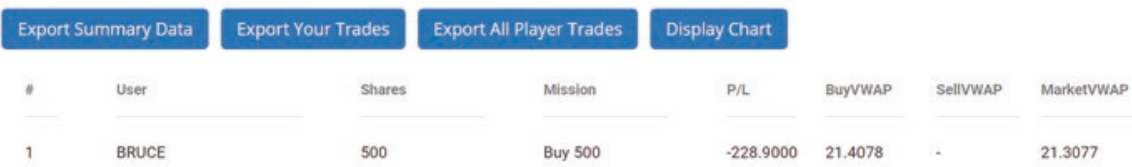

Exhibit 5.7 Post-simulation results - the seller completed the instruction 


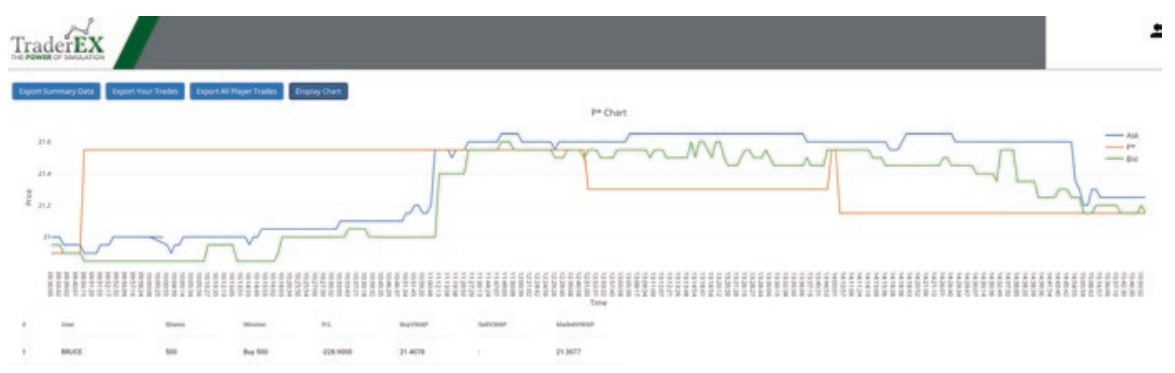

Exhibit 5.8 Post-simulation price chart - the bid and ask quotes and $\mathrm{P}^{*}$ over the trading day

trades early in any up- or downtrends during the day and closed out before the trend is reversed.

The chart that a TraderEx user can display (Exhibit 5.8) shows the evolution of the market quotes and $\mathrm{P}^{*}$ over the course of the trading day. Notice that it takes some time for the informed trading activity to move the price into alignment with $\mathrm{P}^{*}$. For a trader with a buy instruction, the best prices were available early in the day. A trend trader could have profited by buying at 20.20 or so before the price rose to 21. Of course not every price pattern will be advantageous to a trendfollowing buyer.

After reviewing these results and the chart, it is usually good to re-run the simulation and see if you can improve with a new and different $\mathrm{P}^{*}$ path that will almost certainly impact the results you realize.

To review, we completed a large buy or sell order as a buy-side trader in Exercises 1 and 2. In Exercise 3, you traded like a market maker who wants (1) to capture the bid-ask spread by placing limit buy orders below the limit sell orders and, ideally, (2) to transact frequently throughout the day while ending the day with a net zero position (i.e., be neither long nor short the security). Such proprietary traders and speculators usually want to end the day with a zero position, but they are willing to place limit orders on one side of the market (either long or short) for a longer period during the day if they want to bear some uncertain and accept potentially greater position risk. In Exercise 4, you explored the strategy of trying to capture short-term price trends by entering market orders at times when you think prices might be about to make a move upward or downward. In contrast to short-term price speculators, buy-side traders will typically be more patient than proprietary traders and will place limit orders either to build up or to wind down a position based on the systemprovided "Mission" objective.

\subsection{Conclusion}

The TraderEx simulation is an effective learning tool to understand trading and price discovery firsthand while receiving performance feedback on the effectiveness of your decisions. As we have described, effective buy-side trading (e.g., acquiring 
a position at prices less than VWAP) enhances the investment returns of the money managers in charge of the portfolio. Other trading roles such as liquidity provider or trend follower can be tried out in TraderEx. It provides a market experience that imposes illiquidity costs and exposes you to risk. These experiences replicate some of the learning and pressures felt on a real trading desk.

Simulations are an excellent way to "bring to life" many of the financial markets concepts presented in this book. While trading a single fictitious stock over the course of one day cannot capture every aspect of the professional life of a trader, it does offer a helpful introduction, and it provides a good taste of what it is like to be operating at an institutional trading desk.

Open Access This chapter is licensed under the terms of the Creative Commons Attribution 4.0 International License (http://creativecommons.org/licenses/by/4.0/), which permits use, sharing, adaptation, distribution and reproduction in any medium or format, as long as you give appropriate credit to the original author(s) and the source, provide a link to the Creative Commons license and indicate if changes were made.

The images or other third party material in this chapter are included in the chapter's Creative Commons license, unless indicated otherwise in a credit line to the material. If material is not included in the chapter's Creative Commons license and your intended use is not permitted by statutory regulation or exceeds the permitted use, you will need to obtain permission directly from the copyright holder.

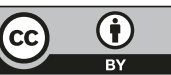

